Available online at www.refaad.com

BAES, 3(2)2019, 84-91

Research Article

Bulletin of Advanced English Studies (BAES)

Journal Homepage: https://www.refaad.com/views/BAES/home.aspx

ISSN: 2617-6459 (Online) 2617-6440 (Print)

\title{
Implications of the Sociocultural Theory on Students' Reading Comprehension
}

\author{
Muhammad Mukhtar Aliyu ${ }^{\text {a* }}$, HalimahSadiyahYakubu ${ }^{b}$ \\ a,b Department of English and Literary Studies, Bauchi State University, Gadau, Nigeria \\ Emails: ${ }^{a}$ mamukhtar@basug.edu.ng, ${ }^{b}$ halimayakubuya@gmail.com
}

\begin{abstract}
In the Nigerian classrooms, teachers focus much attention on the linguistic aspects of the text neglecting the other aspects such as readers and background knowledge in teaching reading comprehension. Therefore, this paper discusses the sociocultural views on reading comprehension and reports students' views of a Problembased learning approach (PBL) on their reading comprehension. Second-year 18 ESL undergraduates were involved in the study for a period of 12 weeks. Semi-structured interviews were used to elicit the participants' views on the use of PBL in reading comprehension. The findings revealed that PBL has a positive impact on participants' reading comprehension. It increased their interests and engagement with texts during reading. The study provides some implications for teaching reading comprehension in the sociocultural context and encourages further research to investigate the effectiveness of instructional approaches that incorporate the sociocultural perspectives on reading comprehension.
\end{abstract}

Keywords: ESL classroom; Nigeria; PBL; reading comprehension; sociocultural theory.

\section{Introduction}

Reading is a language skill that is important in coping with challenges in everyday life. For students at all levels, reading skill is considered as a necessity because it is a tool with which learning takes place and thus, determines the students' success. Therefore, proficiency in reading is required for the students during and after their studies. Despite the importance of reading, many studies reveal that Nigerian students at all levels of education: primary, secondary and tertiary, face various challenges with reading skills. For instance, in secondary school, studies show that the students perform poorly in their reading comprehension examination (Julius, 2015; Yusuf, 2010). Researchers attributed the students' poor performance in reading comprehension to various factors such aspoor reading habit among the students, lack of reading libraries material, lack of motivation and poor teaching method adopted by teachers in reading classrooms (Julius, 2015).

The poor teaching method adopted by the teachers in the reading comprehension classrooms is the concern of this paper. Studies have shown that most of the methods adopted by Nigerian teachers while teaching reading comprehension are ineffective. For instance, many of the teachers adopt the traditional method of teaching which is criticised of rendering the students as passive in the reading comprehension classroom (Udosen, 2011). Some teachers have the wrong notion that students' ability to pronounce words is what reading is all about. They assume that students' reading ability is improved once they can pronounce all the written words correctly, that is, translate writing into speech sounds (Yusuf, 2011).Other teachers only teach the students about reading, that is, increase the students' awareness of the importance of reading comprehension rather than improving their reading performance. In real sense, reading is beyond the ability to pronounce words correctly but includes the recognition and interpretation of the written symbols (Yusuf, 2009).

\footnotetext{
${ }^{*}$ Corresponding author

Email address: mamukhtar@basug.edu.ng (Muhammad Mukhtar Aliyu)

DOI: https://doi.org/10.31559/baes2019.3.2.3
} 
Most of the studies conducted on reading in the Nigerian context do not provide sufficient guidelines for the effective teaching and testing of reading comprehension. Many of the research carried out in reading focus on identifying students' problems in reading comprehension (Don-ezenne, 2014).Researchers like Huwari (2019) reveals some strategies used by Jordanian EFL Jordanian teachers in teaching reading comprehension such as teaching vocabulary and preparation for reading materials Although other studies have tried to provide solutions to the problems of teaching reading comprehension, developing students' reading comprehension is still one of the main problems faced by teachers in ESL classrooms. There is still a need for approaches that would enhance students' reading comprehension ability. Therefore, this study reports students' views on Problem-based learning approach on their reading comprehension in order to make suggestions for reading comprehension teachers. The study also reviews reading comprehension from the sociocultural perspectives so as to encourage researchers to conduct more empirical studies in order to provide effective methods for reading comprehension instructions in the Nigerian context.

\section{Research Question}

The following is the research question of the study

\section{How does the PBL approach influence the participants' reading comprehension?}

\section{The Sociocultural Theory}

The sociocultural theory proposed by Vygotsky (1978) explains human cognitive development based on social and cultural development. According to the theory, cognitive development is connected with culture and society. Learners construct new knowledge through social interaction and collaboration with others. They construct their new knowledge with the help of other learners, the learning context and the environment. Thus, learners' cognitive development depends on the tools provided by society. According to Vygotsky, cognitive development is a process through which learners develop more systematic, logical and rational concepts from their social interactions with the help of a teacher or a peer who is more skilled in the subject. Through the interactions, the learners acquire new knowledge of the world and culture, and strategies for learning.

To further explain the theory, the concept of the zone of proximal development for learning (ZPD) was introduced by Vygotsky (1978). The concept includes two levels of learning based on the theory. The first level is the one already reached by a learner, the actual development level. At this level, a learner is capable of solving a problem independently. The second level is the one yet to be attained by a learner. It is a level of potential development (ZPD) where a learner is capable of reaching with the help of a teacher or more capable peer. Thus, ZPD is described as the range of tasks that are too difficult for a learner to master alone but with the guidance and assistance of a teacher or a more capable peer. The assistance is provided to help the learners to get into their zone of proximal development for learning (ZPD).

In order to facilitate learning to attain the zone of proximal development, Wood, Bruner and Ross (1976) introduced the concept of scaffolding which is related to the ZPD. Wood (1988) defines scaffolding as a 'tutorial behaviour that is contingent, collaborative and interactive'. It is contingent because in the learning process actions (of learners and teachers) influence one another or are influenced by one another. It is also collaborative because learners jointly achieve the result. Finally, because two or more people who are mutually engaged in the activities, it is regarded as interactive. Thus, the support given to a learner, by either a teacher or peers, in a learning process in order to attain ZPD is referred to as scaffolding.

In the reading comprehension, scaffolding refers to any support given to a learner which helps him/her to obtain meaning and get the overall understanding of the content ofa text. For example, before a reading comprehension lesson, a teacher can teach the meaning or pronunciation of a difficult word used in a text. Teachers can also give background knowledge of the text in order to facilitate the students' understanding ofthe meaning of a text. At the end of the lesson, teachers can also ask the students some questions which would also enhance their reading comprehension.

There are some instructional implications of the sociocultural theory. The main implication is that learning occurs through interaction, negotiation, and collaboration among learners. Therefore, supporting students to engage in the activities, talk, and use of tools in order in the learning process should be the goal of teachers. For instance, with the advent of technology, researchers propose that media, like video games, word processors could be used as analytical tools to create new skills and habits in the learners. Thus, teachers can use the technology to facilitate the teaching of reading comprehension through creating asynchronous learning networks. In the learning process, teachers should identify learners' abilities that need to be developed and predict what the learners are capable of doing independently in the future in order to give appropriate supports (Scott \&Palincsar, 2013). In this study, ill-structured problems which are related to their real-life situations were given to the participants, thus providing background knowledge. They were asked to collaboratively work in groups and propose viable solutions to problems. 


\section{Reading Comprehension}

Reading comprehension is broadly described as a process of understanding a written message. In other words, it is a process whereby a person reflects and engages with written texts, in order to achieve some specific goals such as developing his/her knowledge, potentials, and participating in society (OECD, 1999). Other researchers define reading as an 'interactive process in which readers construct a meaningful representation of text using effective strategies' (Gilakjani \& Sabouri, 2016).For Wixson, Peters, Weber, and Roeber (1987), reading is the process of creating the meaning of a text.

According to these scholars, reading is a process that requires the integration of (a) the reader's existing knowledge (b) the text information and (c) the reading context. They highlighted thatthe good readers must in cooperate their knowledge and skills, according to various reading conditions, in the process of constructing meaning for different texts. In addition, good readers must be knowledgeable of various purposes for reading. They should also be aware of effective skills and strategies to be employed in their reading, and how different texts and contextual factors can influence their reading. Finally, good readers should develop positive attitudes about reading and positive perceptions about him/her self as a reader. According to Kintsch(1998), reading comprehension is the process of 'creating meaning' from the text in order to get an 'understanding of the text rather than to acquire meaning from individual words or sentences'.

\section{Sociocultural Perspectives of Reading Comprehension}

From the sociocultural perspectives, reading comprehension is described as the 'process of simultaneously extracting and constructing meaning through interaction and involvement with written language'(RAND Reading Study Group, 2002 p. 11).According to Duke (2003), reading comprehension is a process of making meaning through interaction with a text by combining readers' prior knowledge and previous experience, the information in the text, and the readers' views. In the reading process, the readers evaluate the accuracy of the text to see if it fits their personal agenda by moving through the text and finally arrive at a self-selected location.

Within the sociocultural context, Snow (2002) identifies areas that have an impact on the students' reading comprehension. Thus, teachers should consider them while teaching reading comprehension. These include the text, the activity, and the reader. These areas revolve around the purpose of the reading and interrelate in dynamic ways in the reading process. Snow's (2002) model is presented in Figure 2.1. Although reading comprehension is influenced by these factors, another factor that playsan important role in guiding them is the instructional process adopted by teachers.

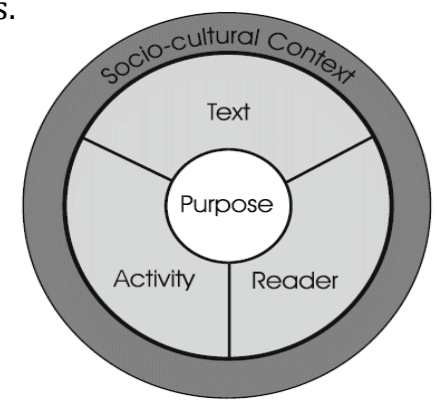

Figure(1): Variables that affect reading comprehension (Snow, 2002)

In the model, Snow views reading comprehension as the product of a complex combination of several interactive factors that need to be considered either individually or in combination in designing reading instruction (Woolley, 2011). Each of these variables/factors is explained in detail in the following section. According to the model, the first factor is the socio-cultural context which contains all cultural practices within the learning context such as the learners, classroom, learning objectives of the lesson. The classroom setting and the objectives of a lesson provide a socio-cultural context within which meaning is constructed. Based on the model, readers play an integral role in effective reading comprehension to take place.

Learner' personal experiences and prior knowledge, as well as social/cultural identities, are also part of the socio-cultural context that play a role in shaping learners' understanding of a text (Woolley, 2011). For example, researchers claim that readers' cultural beliefs and values may influence their comprehension of a text (Kendeou \& van den Broek 2005). Readers' socio-linguistic group, religious or political affiliation may also influence their views, thinking, and comprehension of a text. Thus, for the readers to effectively comprehend a text, there are factors that need to be considered by instructors such as, cognition, motivation, domain and linguistic knowledge. For example, teachers should pay attention to the learners' ability to retain and recall ideas, their interests in reading, knowledge of the topic and familiarisation with the words used. All these factors also depend on the texts in use and the specific activity in which one is engaged.

The textis another variable that affects reading comprehension according to Snow's model. Texts have two features which affect reading comprehension. The first aspect is what readers bring to the reading task in terms of their 'reading skill, language, cognitive processes, background knowledge, interests, goals, and understanding of 
the requirements of a reading task' (Fletcher et al. 1990). The second part is textual features such as 'content, style, linguistics, and cognitive features'. These also play an important role in determining comprehension in reading (Fry 2002). Mostly, the difficulties encountered by readers in reading comprehension could be as the result of the interaction of these elements. Therefore, teachers should pay attentionto them, as a textmay be difficult, depending on its relationship with the learner's knowledge and abilities and its requirements.

When a reader engages in a reading activity, he/she does it for a purpose which he/she intends to achieve at the end. Thus, a reading activity involves the reader's purpose(s) which determines its success. The general purpose can be either externally imposed such as preparing for the examination. The reader's purpose could be influenced by other motivational variables, such as his/her interest and prior knowledge. According to Free body and Luke (1990), in reading comprehension, readers assume 'four different roles: (1) a code breaker, (2) a textparticipator, (3) a text-user, and (4) a text analyser'. To break the code, a reader is required to understand the conventions of written and spoken language as well as the visual multimodal of the surface features of the texts. To participate in a text, a reader should make meaning by drawing from his/her social and cultural backgrounds and prior knowledge within literate contexts. As a text-user, a reader should understand the purposes of using texts in different ways for different cultural and social functions. The text analysing role focuses on the ideas within the literacies.

From the discussion so far, it has been seen that reading comprehension is an active process where by readers construct meaning through with a text by combining their prior knowledge and experience, the information in the text, and their views of the text. Learning generally according to the sociocultural theory is a process through which learners acquire knowledge from interactions with peers and experts that are more knowledgeable. With the guidance and support of their peers and experts, learners become more capable of performing tasks that are slightly beyond their own independent knowledge and ability. As such, they become more knowledgeable and experienced with the task, the supports are withdrawn while they internalise the acquired knowledge and experiences (Vygotsky, 1978).

Therefore, Pardo (2004) provides some suggestions which teachers should adopt in their classrooms to support their students' reading comprehension. Teachers should 'teach decoding skills, help students build fluency, build and activate background knowledge, teach vocabulary words, motivate students, and engage them in personal responses to the text'. For instance, students' interests, choices, fields of study and culture should be considered while selecting a reading text. This would motivate the students and allow them to have more background knowledge and make connections with the previous knowledge in order to create meaning and make sense of what is being read. Visual or graphics could be used to make the students activate their prior knowledge. Teachers should also 'teach text structures, model appropriate text selection, and provide regular independent reading time for the students'. This would make the students' comprehension of the text more easily. They should also 'teach students to monitor and repair, use multiple strategy approaches, scaffold support, and make reading and writing connections visible to students'.

\section{Current Study}

Based on the previous discussion, this study employs the PBL approach in order to obtain students' views on reading comprehension. The rationale behind using PBL because the approach takes Sociocultural theory and Snow's (2002) model into consideration. The approach developed based on the constructivist theory of learning. Learning is contextualised into a real-life situation where students learn collaboratively while solving a real-life problem (Jonassen, 1997; Mardziah H. Abdullah, 1998). The goal of PBL is to encourage learners to develop essential skills such as problem-solving skills, flexible knowledge, intrinsic motivation, collaborative and selfdirected learning (Barrows, 1996). The students take the major responsibility for their learning while teachers only facilitate, guide and monitor the students' learning through open-ended questioning, stimulating the students' abilities to analyse information, to focus on the learning objectives, assist the students in identifying appropriate resources to obtain the required information and apply new information to their problem-solving work and finally withdraw their support when the students could do it alone (Hmelo-silver \& Barrows, 2006).

The students work in small groups, deliberate, discuss, share expertise, support one, discover for themselves and agree on what and how to learn it to solve an ill-structured problem (Mardziah H. Abdullah, 1998).They would also consult sources such as textbooks, library and online material to get more information about the solutions to the problems. An ill-structured problem is a problem related to their real-life situation but its descriptions are not clearly defined and are complex enough to stimulate the students' thinking (Jonassen, 1997). There could be various solutions to the problem based on students' perceptions and interpretations (Shin, Jonassen, \& McGee, 2003).

\section{Methodology}

\subsection{Participants}

Eighteen (18) second-year undergraduates in an English composition class in North-Eastern Nigeria were selected for the study. They are an intact class of mixed-gender with ages from 24 to 38 years old. They share the 
same first language and culture and had no prior experience of group learning. For the purpose of the study, they were assigned into three groups through self-selection.

\subsection{Procedures}

The whole PBL process was given in 12 weeks, which were separated into two cycles. In both cycles, the participants were given an ill-structured problem and asked to collaboratively work under tutors' facilitation and propose viable solutions in three weeks. The first and second weeks were preliminary. In week 3 , an ill-structured problem was given to each group and they were asked to propose viable solutions following Savery and Duffy (1995) model of PBL. The stages are as follows:

- 'Generate working ideas or possible solutions;

- Identify available information related to the problem;

- Identify learning issues (things they need to find more information about);

- Identify resources to look up or consult;

- Assign tasks to the various group members (i.e. share the learning issues);

- Gather information (conduct self-directed learning);

- Propose solution(s)'.

The problem is related to Boko Haram insurgency which caused some students to transfer their studies to other areas while some abandoned school completely. The second ill-structured problem is on undergraduates' poor academic performances and studies attitudes mainly due to excessive engagement with social media. Through interactions, the participants brainstormed and generated possible solutions to the problem. They also identified learning issues, namely, things they need to find out more information about. Thereafter, they divided the learning issues among them and identified resources to look up or consult (reading materials). They gathered the information through self-directed learning and reading. Finally, each group proposed viable solutions problem and presented orally to the class, and eventually submitted the written to the lecturer. The process lasted from weeks 3-5. In week 6,a debriefing session was conducted by the researchers and discussed unclear issues related to the procedures with the participants. The procedures were repeated in the second cycle in weeks 7-10. At the end of the PBL process, the participants were interviewed to get perceptions and opinions.

\subsection{Instruments}

A semi-structured interview was conducted at the end of the treatment to collect data for the study. Ten participants were interviewed for 15-20 minutes each until data saturation was achieved. They were interviewed in order to obtain information on how the PBL process help to develop their reading comprehension. Specifically, self-directed learning and group reading. The interviews were recorded, transcribed, coded and categorised into themes based on the emerging themes to answer the research question.

\section{Findings}

From the responses of the interview, all the participants revealed that the use of the PBL approach helped them in their reading comprehension. To answer the research question, two major themes were identified: PBL approach increases the participants' interest in reading texts during the self-directed learning. It is also discovered that the approach helped to increase the participants' engagement with the text during reading.

\section{PBL Approach Increases the Participants' Interest in Reading Texts}

It is revealed that the use of ill-structured problems helped the participants to develop more interest in reading. This is mostly because the ill-structured problems are related to their real-life situations and they really wanted to have lasting solutions to the problems. They also related what they read to what they already knew about the problems. For instance, one of the participants, Binta explained that the ill-structured problems stimulated her interest in reading because she wanted to know more about the problems and find a solution to the problems. The issue Boko Haram is a problem everyone would like to find solutions to it. Therefore, she consulted many materials in the library and online in order to propose viable solutions to the problem.

\section{Actually, it increases my interest in reading because the problems affect my life, my state and my country. So, I want to read many materials in order to find solutions.}

Another participant, Abubakar also revealed that some of his friends and relatives were kidnapped by the terrorists. As such when they were given the ill-structured related to that and were asked to propose solutions to the kidnapping problems, he was so motivated to different materials to help them proffer the solutions.

\section{The Approach Helps to Increase the Participants' Engagement with the Text}

It is further discovered that the group interactions helped the participants to develop not only interest in reading but to be more engaged with the reading materials. According to Habib, PBL did not only stimulate his interest in reading but also make him engaged with the texts. He explained that because he would be asked in the subsequent meeting to brief his group members about his findings, he paid more attention during the reading process and made sure he understood the text very well.

Really, I am expected to report my findings to my group members. So, I was very careful and make sure I understand what I read. If not, I cannot explain it to them. 
Umar on his part added that his background knowledge and experience on the topic not only help to be more engaged with the text but also allow him to read faster and understand easily. The findings have supported the Sociocultural theory of learning which suggest that relating learning to students' background knowledge and interactions during the learning process help students to achieve their learning goals.

Another participant, Yunus explained that the approach encouraged him to think critically during the process. A number of things encouraged the participants to think of more ideas related to the writing content. According to Yunus that the ill-structured problems given to them during the PBL activities motivated him to think and have many ideas while reading relevant materials. This is because the ill-structured problems were related to the participants' real-life. It was easy for everyone to contribute his or her ideas in the discussion. Also, due to the complexity of the ill-structured problems, the participants viewed the problems from various perspectives. This prompted their thinking and allowed them to build from one another's idea.

\section{Discussions}

The findings of the study confirm Vygotsky's (1978) concept of the zone of proximal development for learning (ZPD). Through peer and teacher supports, the participants became more engaged with the text and developed interest unlike when working alone. The findings also concur with the assertions of Woolley, (2011) that learner' experiences, background knowledge play a role in shaping their understanding of the text as the illstructured problems given in this study are related to the participants' real-life situations.

The findings are also in line with that of Kunaviktikul, Klunklin and Williams (2008) who discovered that that PBL promotes students' critical thinking skills. Thus, it is not surprising that the approach helps students in reading comprehension because reading involves critical thinking. In addition, Jones, Epler, Mokri, Bryant, and Paretti (2013) reveal that PBL motivates students to learn engineering capstone courses. Therefore, it could be easier in motivating other students in reading comprehension. In other language skills, studies have shown a positive influence of PBL on students' performance. Norzaini Azman and Shin (2012) discovered its positive impact on the students' language skills particularly on their speaking skills. Othman and Ismail Ahamad Shah (2013) also observed its positive effects on the acquisition of the course content and language development of the students.

\section{Implications}

A number of theoretical and pedagogical implications can be derived from this paper. Theoretically, the study reaffirms the sociocultural theory that learning occurs within a sociocultural setting through interaction with peers and more knowledgeable fellow(s).Specifically, the paper confirms that the sociocultural theory could be incorporated in the reading comprehension classrooms particularly in the ESL contexts. The paper shows that students can be supported to attain their ZPD levels in reading comprehension. Therefore, researchers should investigate the effectiveness of instructional approaches that incorporate the sociocultural theory in order to provide teachers with alternative methods.

From the pedagogical perspectives, incorporating the sociocultural theory in the reading comprehension classroom might help in solving some of the problems of teaching and learning reading classrooms in the Nigerian context as mentioned previously. The ill-structured problems help them to create the meaning of what the read by integrating their knowledge and skills as they construct meaning for different texts under a variety of reading conditions. It also helped them to develop positive attitudes about reading and positive perceptions about him/herself as readers.

For the teachers, the study creates teachers' awareness of the need to adopt instructional approaches that would engage and encourage their students to support one another in the reading comprehension classrooms. The approaches would also allow the teachers to support and monitor the students reading process and assess their reading performance. For instance, teachers should focus more on the students during the reading comprehension instruction. While selecting a reading text, they should consider the students' understanding, background, educational level, and complexity of the text. They should also allow the students to work in peers and small group while providing supports in the process. Teachers can give other activities such as pre-reading, while-reading and after-reading activities which are believed to effective in developing students' reading comprehension (Huwari, 2019).

\section{Conclusion}

The objective of the paper is to examine PBL's influence on the participants' reading comprehension. The findings show that the approach increases the participants' interest in reading texts. It also encourages them to be more engaged with the text. The study is limited to a small number of participants and did not measure their reading comprehension ability before and after the study. Thus, future studies can use a larger number of students and can adopt an experimental research design. The student concludes that students could be motivated and become more engaged with the text when it is related to their prior knowledge. Their interests may also be easily 
stimulated when they are supported by peers and teachers in the reading process, and when their choices, fields of study and culture should be considered while selecting a reading text. Eventually, they develop their reading comprehension skills.

\section{Biography:}

Muhammad Mukhtar Aliyu is a lecturer in the Department of English and Literary Studies, Bauchi State University, Gadau, Nigeria. He earned his PhD in English and Applied Linguistics from Universiti Putra Malaysia. His research interests include applied linguistics, collaborative learning and ESL writing.

Halima Sadiya Yakubu is also a lecturer in the Department of English and Literary Studies, Bauchi State University, Gadau, Nigeria. She holds an M. A. in Applied Linguistics. His research interests include applied linguistics, reading and writing.

\section{References:}

[1] Ahmadi. M. R., \& Gilakjani. A. P., Reciprocal teaching strategies and their impacts on English reading comprehension, Theory and Practice in Language Studies, 2(10)(2012),2053-2060, https://doi.org/10.4304/tpls.2.10.2053-2060

[2] Barrows. H. S., Problem-based learning in medicine and beyond: A brief overview. In L. Wilkerson \& W. H. Gijselaers (Eds.), Bringing problem-based learning to higher education: Theory and practice (pp. 3-12). San Francisco: Jossey Bass, (1996)

[3] Don-Ezenne. I. N., Identification and analysis of problems of word recognition in reading among JSS students in Gwgwalada and Kwali area councils of federal capital territory, Abuja, Journal of Research \& Method in Education, 4(5)(2014), 07-14, https://doi.org/10.9790/7388-04530714

[4] Duke. N., Comprehension instruction for informational text. In Presentation at the annual meeting of the Michigan Reading Association, Grand Rapids, MI, (2003)

[5] Fletcher. C. R., Hummel. J. E., \& Marsolek. C. J., Causality and the allocation of attention during comprehension, Journal of Experimental Psychology: Learning, Memory, and Cognition, 16(2)(1990), 233240, https://doi.org/10.1037/0278-7393.16.2.233

[6] Freebody. P., \& Luke. A., Literacies' Programs: Debates and Demands. Prospect, Australian Journal of TESOL, 5(7)(1990), 7-16.

[7] Fry. E., Readability versus levelling, The Reading Teacher, 56(2002), 286-291.

[8] Gilakjani. A. P., \& Sabouri. N. B., How can students improve their reading comprehension skill?, Journal of Studies in Education, 6(2)(2016), 229-240, https://doi.org/10.5296/jse.v6i2.9201

[9] Hmelo-silver. C. E., Barrows. \& Barrows. H. S., Goals and strategies of a problem-based learning facilitator, Interdisciplinary Journal of Problem-based Learning, 1(1)(2006), 21-39, https://doi.org/10.7771/1541-5015.1004

[10] Huwari. I. F., A study on the influence of Jordanian EFLteachers experience in teaching reading comprehension, Asian Journal of Social Sciences \& Humanities, 8(3)(2019), 73-90

[11] Jonassen. D. H., Instructional design models for well-structured and ill-structured problem-solving learning outcomes, Educational Technology Research and Development, 45(1)(1997), 65-94, https://doi.org/10.1007/bf02299613

[12] Julius. A. T., Appraisal of seven critical reading strategies employed by teachers in Ogun State senior secondary schools to teach reading comprehension, African Journal for the Psychological Studies of Social Issues, 18(1)(2015), 142-153.

[13] Kendeou. P. \& P. van den Broek., The effects of readers' misconceptions on comprehension of scientific text. Journal of Educational Psychology, 97(2)(2005), 235-245, https://doi.org/10.1037/0022-0663.97.2.235

[14] Kintsch. W., Comprehension: A paradigm for cognition. Cambridge, UK: Cambridge University Press, (1998)

[15] Mardziah. H. Abdullah., Problem-based learning in language instruction: A constructivist model. ERIC Clearinghouse on Reading English and Communication Bloomington, (1998), 1-6. 
[16] Mardziah. H. Abdullah, \& Tan. B. H., Wired together : Collaborative problem-based language learning in an online forum. Malaysia Journal of ELT Research, 4(2008), 54-71.

[17] Norzaini Azman, \& Shin. L. K., Problem-based learning in English for a second language classroom: Students' perspectives, The International Journal of Learning, 18(6)(2012), 109-126, https://doi.org/10.18848/14479494/cgp/v18i06/47648

[18] Organization for Economic Cooperation and Development (OECD), Measuring student knowledge and skills: A new framework for assessment. Paris: Author, (1999)

[19] Othman. N., \& Ismail Ahamad Shah. M., Problem-based learning in the English language classroom. English Language Teaching, 6(3)(2013), 125-134, https://doi.org/10.5539/elt.v6n3p125

[20] Pardo. L. S., What every teacher needs to know about comprehension, The Reading Teacher, 58(3)(2004), 272-280, https://doi.org/10.1598/rt.58.3.5

[21] Rand reading study group, Reading for understanding. Toward an R\&D program in reading comprehension. The USA. Rand publishers, (2002)

[22] Scott. S., \& Palincsar. A., Sociocultural theory. The Gale Group, Inc,(2013), Retrieved from http://drhatfield.com/theorists/resources/sociocultural_theory.pdf

[23] Shin. N., Jonassen. D. H., \& McGee. S., Predictors of well-structured and ill-structured problem-solving in an astronomy simulation, Journal of research in science teaching, 40(1)(2003), 6-33, https://doi.org/10.1002/tea.10058

[24] Snow. C.E., Reading for understanding: Toward a research and development program in reading comprehension. Santa Monica: Rand Corp, (2002) Retrieved from http://www.rand.org/publications/MR/MR1465/.

[25] Udosen. A. E., The state of reading instruction in secondary schools in Akwalbom state: Implication for sustainable development, Journal of Emerging Trends in Educational Research and Policy Studies, 2(5) (2011), 382-387.

[26] Vygotsky. L. S., Mind in society: The development of higher psychological processes, Cambridge: Harvard University Press, (1978)

[27] Wixson. K. K., Peters. C. W., Weber. E. M., \& Roeber. E. D., New directions in statewide reading assessment, The Reading Teacher, 40(8)(1987), 749-754.

[28] Wood. D., Bruner. J. \& Ross. G. (1976), The role of tutoring in problem-solving, Journal of Child Psychology and Psychiatry, 17(2), 89-100, https://doi.org/10.1111/j.1469-7610.1976.tb00381.x

[29] Wood. D.J. , How children think and learn. Oxford: Blackwell, (1988)

[30] Woolley. G., Reading comprehension: Assisting children with learning difficulties, Springer Science +Business Media B.V., (2011)

[31] Yuan. H., Kunaviktikul. W., Klunklin. A., \& Williams. B. A., Improvement of nursing students' critical thinking skills through problem-based learning in the People's Republic of China: A quasi-experimental study. Nursing and Health Sciences, 10(1)(2008), 70-76, https://doi.org/10.1111/j.1442-2018.2007.00373.x

[32] Yusuf. H. O., A comparative study of the effectiveness of language development and vocabulary methods in teaching reading comprehension in primary schools: Implication for teachers and curriculum planners. Educational Research, 1(8)(2010), 276-284.

[33] Yusuf. H. O., Strategies for improving the teaching of reading Comprehension in Primary Schools, Journal of Educational Research and Development, 4(3) (2009), 63-68.

[34] Yusuf. H. O., Towards improvement in the teaching of reading comprehension in primary schools: The need to activate pupils' relevant schema, Theory \& Practice in language studies, 1(1)(2011), 16-20, https://doi.org/10.4304/tpls.1.1.16-20 